\title{
Prevalence of infected chronic wound isolates and their Minimum inhibitory concentrations against third generation cephalosporins at Mbarara Regional Referral Hospital, Uganda
}

Wangoye Khalim ( $\nabla$ khalimwags@gmail.com ) Mbarara University of Science and Technology

Mwesigye James

Mbarara University of Science and Technology

Tungotyo Martin

Mbarara University of Science and Technology

Twinomujuni Silvano Samba

Mbarara University of Science and Technology

\section{Research Article}

Keywords: Antibiotic resistance, Biofilms, empirical therapy, chronic wounds, infection, cephalosporins, MIC, culture and sensitivity

Posted Date: June 25th, 2021

DOl: https://doi.org/10.21203/rs.3.rs-641034/v1

License: (9) This work is licensed under a Creative Commons Attribution 4.0 International License.

Read Full License 


\section{Abstract}

Background: Globally, the burden of infected chronic wounds is likely to increase due to the rising levels of bacterial resistance to antibiotics and non-communicable diseases such as Diabetes mellitus and cancer. Furthermore, the burden of antibiotic resistant strains in infected chronic wounds is likely to increase especially in resource constrained areas like Mbarara regional referral Hospital where the selection of antibiotic therapy does not usually depend on known antibiotic susceptibilities. Therefore the objectives of this study were; (I) to determine the prevalence of infected chronic wounds isolates from patients admitted in the surgical ward of MRRH, Uganda and (II) to determine the MIC of infected chronic wound isolates against the third generation cephalosporins.

Method(s): This study was a descriptive analytical survey of bacterial isolates from infected chronic wounds among patients admitted in the surgical ward of MRRH, Uganda. Seventy five (75) study participants were recruited in the study using convenient sampling technique. Wound swabs were aseptically collected, registered in the laboratory register and depending on the nature of samples; each specimen was inoculated on chocolate, blood, mannitol salt sugar, xylose lysine decarboxylated agar, and MacConkey Agar and incubated at $35^{\circ} \mathrm{C}-37^{\circ} \mathrm{C}$ in the incubator. Broth microdilution method was used to test for MIC.

The collected data was entered into Microsoft Excel and exported to STATA version 15.0 for statistical analysis. Chi square/Fishers's Exact test and analysis of variance (ANOVA) tests were used to analyse data for objective 1 and 2 respectively.

Results: The most prevalent pathogens isolated were staphylococcus aureus (40.6\%,) and Klebsiella spp $(29 \%)$, while the least prevalent pathogens were Providencia $\operatorname{spp}(1.4 \%, \mathrm{n}=1 / 69)$ and Enterobacter $\operatorname{agglomerans}(2.9 \%, n=2 / 29)$. Generally, staphylococcus aureus exhibited the lowest MIC against cefoperazone+sulbactum $2 \mathrm{~g}\left(\right.$ Sulcef $\left.^{\circledR}\right)$ and ceftriaxone $1 \mathrm{~g}\left(\right.$ Epicephin $\left.^{\circledR}\right)(4.33 \pm 8.41 \mu / \mathrm{ml}$ and $15.77 \pm 23.32 \mu / \mathrm{ml}$ respectively). However, the differences in mean MIC observed across various groups were not statistically significant $(P>0.05)$.

Conclusion: The most prevalent pathogens isolated from patients with infected chronic wounds at the surgical ward of MRRH were Staphylococcus aureus, Klebsiella spp and proteus spp and the most effective third generation cephalosporins were cefoprazone+sulbactam $2 \mathrm{~g}$ and ceftriaxone $1 \mathrm{~g}$ (Epicephin ${ }^{\circledR}$ ) while the most ineffective antibiotics were cefpodoxime $200 \mathrm{mg}$ and cefixime $400 \mathrm{mg}$.

\section{Background}

Globally, the burden of infected chronic wounds is likely to increase due to the rising levels of bacterial resistance to antibiotics and non-communicable diseases such as Diabetes mellitus and cancer (1). In the United States of America alone, more than 6.5 million chronic wounds with evidence of bacterial infection are diagnosed every year (2). Furthermore, the burden of antibiotic resistant strains in infected chronic wounds is likely to increase especially in resource constrained areas like Mbarara regional referral 
Hospital where the selection of antibiotic therapy does not usually depend on known antibiotic susceptibilities (3).

Moreover, routine culture and sensitivity tests and periodic antibiotic resistance surveillance studies are rarely performed in Mbarara Regional Referral Hospital due to inadequate microbiology supplies and the turnaround time for culture and sensitivity tests is high in the majority of Hospitals in Uganda, causing delays in making clinical decisions required for selection of effective antibiotic therapy (4).

Although ceftriaxone has been recommended as the drug of choice in the management of severe bacterial infections in Uganda's clinical guidelines, $81 \%$ of the prescriptions reviewed indicates inappropriate use of ceftriaxone, increasing the risk of bacterial resistance to ceftriaxone and other cephalosporins (5). In addition, the absence of antibiotic therapy guidelines for management of infected chronic wounds promotes indiscriminate use of cephalosporins, increasing the risk of bacterial resistance to cephalosporins as well as complicating the care of infected chronic wounds (6).

Consequently, patients with infected chronic wounds are likely to experience long hospital stays, high treatment costs, further delay of wound healing, development of severe invasive bacterial infections and increased emergency of antibiotics resistance if ineffective antibiotics are used

Therefore this study was conducted to generate the local pathogen prevalence maps and minimum inhibitory concentrations (MIC) of third generation cephalosporins, so as to guide Clinicians to make evidence-based prescription of third generation cephalosporins required for timely and effective management of infected chronic wounds as well as dose optimization and individualization.

\section{Methods}

\section{Study design}

The study was a descriptive analytical survey of bacterial isolates from infected chronic wounds at the surgical ward of MRRH from August 2020 to October 2020.

\section{Study setting.}

Participants were enrolled from the surgical ward of MRRH between August 2020 and October 2020. MRRH is a public health facility with a bed Capacity of 300 beds and it is a Regional Referral Hospital in Western Uganda located in Mbarara Municipality, approximately $250 \mathrm{~km}$ from Kampala, the capital City of Uganda. Its catchment population is approximately 10 million people. This Hospital also serves as a Teaching Hospital for MUST. According to the patient discharge register, the average number of patients admitted with a diagnosis of various infected wounds is 35 patients per month with an annual prevalence of 420 patients. The surgical ward is currently run by 10 nurses, 25 residents, 4 general surgeons, 1 plastic surgeon, 1 orthopedic surgeon, 1 pharmacy technician, 1 Hospital Pharmacist and 1 neurosurgeon. The surgical ward is subdivided into the male and female sections with a total bed capacity of 55 . 
The microbiological procedures were carried out in the Microbiology Laboratory of MUST, Mbarara City, Uganda. The Microbiology Laboratory is managed by three highly experienced staff that is 2 Laboratory technologists and 1 senior laboratory technologist. The Laboratory is well equipped with the necessary equipment and materials including equipment such as electronic microscopes, florescent microscopes, biosafety cabins, incubators, autoclaves, analytical profile index analyzer and polymerase chain reaction (PCR) machine. Therefore, the Laboratory is able to offer a range of laboratory tests such as gram staining, microscopy, culture and sensitivity tests, Liver function tests and serological tests such as typhoid test, Brucella agglutination test and Human immunodeficiency test (HIV) serology).

In addition, this Microbiology Laboratory follows stringent Laboratory quality assurance measures from the Central public health Laboratory of Uganda that have been designed based on the recommendations of Clinical Laboratory standard Institute.

\section{Study population:}

The study population was patients with infected chronic wounds admitted at the Surgical Ward of MRRH in Uganda.

\section{Selection criteria:}

All inpatients admitted in the surgical ward with signs and symptoms of infected chronic wounds (increasing pain at the ulcer site, erythema, edema, heat, purulent exudate, serous exudate, delayed ulcer healing, discolored granulation tissue, friable granulation tissue, wound base pocketing, foul odor and wound breakdown) and consented to participate in the study were included in this study while patients without record of medication history and those who expressed voluntary withdrawal were excluded.

\section{Sample size:}

The following assumptions were made during sample size calculation;

1. Research data was collected for 3 months and the expected population of patients with infected wounds was 105 patients in 3 months (approximately 35 patients per month). This assumption was based on a review of primary data from the patient discharge register in the surgical ward which had 420 patients with a diagnosis of various infected wounds in one year (2018).

2. The prevalence of infected chronic wounds was estimated to be $22 \%(7)$.

\section{$N_{0}=Z^{2 \star P}(1-P) / E^{2}$}

$\mathbf{N}_{\mathrm{o}}=$ Sample size

Z= Confidence level.

$\mathbf{P}=$ Estimated proportion of infected chronic wounds in the population. 
$\mathbf{E}=$ Desired level of precision.

$Z=1.96, P=0.22(22 \%), E=0.05$

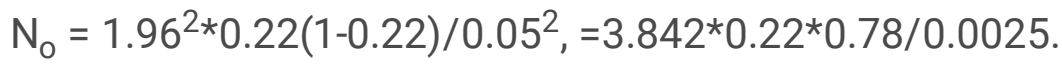

$=264$ Patients.

Finite population correction (8): This was required because the expected average population of patients in three months of data collection was 105 patients based on the above record in the surgical ward.

$\mathrm{n}=\mathrm{N}_{\mathrm{o}} /\left(\mathrm{N}_{\mathrm{o}}-1\right) / \mathrm{N}+1$,

$\mathrm{n}=$ Adjusted Sample size.

$\mathrm{N}_{\text {= }}$ Population size (105 patients).

$\mathrm{n}=264 /(264-1) / 105+1, \mathrm{n}=264 / 3.5=75$ patients.

\section{Sampling Technique}

Convenience sampling technique was used to select the study subjects who met the criteria for infected chronic wounds (9).

\section{Study procedures:}

For diagnosis of infected chronic wounds, a checklist containing symptoms and signs of chronic infected wounds was used by the Clinician to guide the clinical diagnosis of chronic infected wounds.

\section{Sample Collection and Bacterial identification:}

Two nurses working in the surgical ward were trained by an experienced laboratory technologist to empower them with skills of obtaining wound swabs for culture and sensitivity.

After obtaining an informed consent from the patients meeting the criteria, routine clinical samples were aseptically collected by a trained nurse from the patients' wound base using sterile cotton swabs. The standard operating procedure developed by British Columbia Provincial Nursing Skin \& Wound Committee were used to ensure an aseptic procedure (10). The samples were transported to the Microbiology Laboratory of MUST within 30 minutes. Only one swab was obtained from each patient after cleaning the wound base with sterile normal saline.

\section{Laboratory procedures}

I. Primary cultures: On receipt, swab specimens were registered in the laboratory research register. 
II. Depending on the nature of samples, each specimen was inoculated on chocolate, blood, mannitol salt sugar, xylose lysine decarboxylated agar, and MacConkey Agar as follows; and incubated at

III. Using inoculating loop, each sample was streaked onto the upper one fourth portion of an agar plate with parallel overlapping strokes. The plates were labeled.

IV. The loop was flamed and allowed to cool. The plate was turned at right angle. Overlapped the previous streak once or twice and repeated the streaking process on one-half of the remaining area.

V. Procedure 4 was repeated.

VI. The plates were incubated overnight at $35^{\circ} \mathrm{C}-37^{\circ} \mathrm{C}$ in the incubator.

VII. After incubation for 16-20 hours, the plates were checked for bacterial growth.

VIII. Representative bacterial colonies were selected based on the difference in shape, size and color. Selected colonies from each plate were sub-cultured and incubated overnight.

IX. Bacterial identification: This was performed based on morphological, cultural characteristics such as hemolysis on blood agar, swarming (positive for proteus spp), changes in physical appearance on differential agar (pink appearance of lactose-fermenting bacterial colonies on macConkey agar), motility test was positive for enterobacter agglomerans and providencia spp. In addition, the following biochemical tests were performed to confirm the identity of bacterial pathogens;

\section{Table 1: Biochemical tests for Identification of bacterial pathogens.}

\begin{tabular}{|l|l|l|}
\hline Isolate & Biochemical test & Results \\
\hline \multirow{4}{*}{ Staphylococcus aureus } & Catalase & Positive \\
\cline { 2 - 3 } & Coagulase & Positive \\
\cline { 2 - 3 } & Mannitol fermentation & Positive \\
\cline { 2 - 3 } & Dnase & Positive \\
\hline \multirow{3}{*}{ Klebsiella spp } & Citrate & Positive \\
\cline { 2 - 3 } & Urea & Positive \\
\cline { 2 - 3 } & Indole & Negative \\
\hline \multirow{3}{*}{$\begin{array}{l}\text { Enterobacter } \\
\text { agglomerans }\end{array}$} & Hydrogen sulphide & Positive \\
\cline { 2 - 3 } Providential spp & Urea & Positive \\
\cline { 2 - 3 } & Citrate & Positive \\
\cline { 2 - 3 } & Oxidation & Negitive \\
\cline { 2 - 3 } & Hydrogen sulphide \\
\cline { 2 - 3 } & Urea & Negative \\
\cline { 2 - 3 } & Indole & Negative \\
\hline & catalase methyl red, citrate, nitrate reductase and & postive \\
& & \\
\hline
\end{tabular}

\section{Antibacterial susceptibility Testing:}


The minimum inhibitory concentrations and antibacterial susceptibility testing were performed using broth microdilution technique as described by CLSI and the review in the general principle and practices of antimicrobial susceptibility testing (11). The Procedure for Broth microdilution involved the following steps;

1. Preparation of stock solutions: Stock solutions were prepared based on the manufacturer's instruction for reconstitution. All the 5 antibiotic brands did not have potency information and the weight for antibiotics were calculated based on the highest plasma concentrations derived from the following pharmacokinetic studies because of the correlation that exist between MIC and pharmacokinetic parameters (12).

\section{Table 2: Weight of powder for stock solutions.}

\begin{tabular}{|c|c|c|c|c|}
\hline Ino. & Antibiotic. & $\begin{array}{c}\text { Maximum plasma } \\
\text { concentration (desired } \\
\text { concentration). }\end{array}$ & Reference. & $\begin{array}{l}\quad \text { Weight of powder(g) } \\
\text { (desired concentration) X } \\
\text { volume of diluent }(1000 \mathrm{ml} \text { ) } \\
\text { divide by } 1000000\end{array}$ \\
\hline 1 & $\begin{array}{l}\text { Ceftriaxone } 1 \mathrm{~g} \\
\left(\text { Epicephin }{ }^{\circledR}\right)\end{array}$ & $168 \mu \mathrm{g} / \mathrm{ml}$ & (13). & $0.168 \mathrm{~g}$ \\
\hline 2 & $\begin{array}{l}\text { Cefoperazone+ } \\
\text { Sulbactam } 2 g \\
\left(\text { Sulcef }^{\circledR}\right)\end{array}$ & $159 \mu \mathrm{g} / \mathrm{ml}$ & $\begin{array}{l}\text { (Rosenfeld } \\
\text { et al., } \\
1983)\end{array}$ & $0.159 \mathrm{~g}$ \\
\hline 3 & $\begin{array}{l}\text { Cefotaxime } 1 \mathrm{~g} \\
\left(\text { Omnatax }{ }^{\circledR}\right)\end{array}$ & $41.1 \mu \mathrm{g} / \mathrm{ml}$ & (14). & $0.0411 \mathrm{~g}$ \\
\hline 4 & $\begin{array}{l}\text { Cefpodoxime } \\
\text { 200mg } \\
\left(\text { Ximeprox }^{\circledR}\right)\end{array}$ & $2.7 \mu \mathrm{g} / \mathrm{ml}$ & (15) & $0.0027 \mathrm{~g}$ \\
\hline 5 & $\begin{array}{l}\text { Cefixime } \\
400 \mathrm{mg} \\
\text { (gramocef-o } \\
\left.400^{\circledR}\right) .\end{array}$ & $2.47 \mu \mathrm{g} / \mathrm{ml}$ & (16) & $0.00247 \mathrm{~g}$ \\
\hline
\end{tabular}

The antibiotic solutions were kept in the refrigerator at a temperature of $4^{0} \mathrm{C}$.

I. Using a pipette, $100 \mu \mathrm{l}$ of sterile brain heart infusion were dispensed into the wells of microtitre plates, each row labeled to corresponding antibiotic.

II. $100 \mu$ l of the antibiotic stock solution were also dispensed into the well in column 1 . Using the pipette set at $100 \mu \mathrm{l}$, mix the antibiotics into the wells in column 1 by sucking up and down 6 times. 
III. $100 \mu$ l of this were withdrawn from column 1 and added to column 2, making column 2 a two-fold dilution of column 1.

IV. $100 \mu$ l of column 2 were transferred to column 3. This was repeated down to column 9.

V. $5 \mu$ l of isolates suspended in sterile water and adjusted to McFarland turbidity $\left(10^{4} \times 10^{5} \mathrm{CFU} / \mathrm{ml}\right)$ were dispensed into the wells except wells in column 11 for sterility control. Wells in column 10 were used for growth control and contained $100 \mu$ of brain heart infusion and $5 \mu \mathrm{l}$ of isolates.

VI. Microtitre plates were then covered with sterile aluminum foil to prevent evaporation during incubation.

VII. After 24 hour incubation at $37^{\circ} \mathrm{C}$, the microtitre plates were observed using a reading mirror for visible bacterial growth as indicated by turbidity. The smallest concentrations of antibiotics that inhibited growth were recorded as the MIC.

\section{Quality control:}

To ensure consistent and high quality research outputs, the researcher implemented quality control measures throughout the entire research process. Antibiotics for the third generation cephalosporins, culture media and staining reagents were procured from premises licensed by the National Drug Authority of Uganda to avoid the risk of counterfeit products which could affect the quality of research results. Inaddition, the procured antibiotics, culture media and staining reagents were strictly stored at conditions specified by the manufacturers to avoid product deterioration during the research process.

\section{Data processing and Analysis Plan:}

The study data was entered into Microsoft Excel and exported to STATA version 15.0 for statistical analysis. Frequencies, and mean (SD; standard deviation) were computed to summarize the data.

- Objective 1: The prevalence of pathogens was first summarized as proportions and to determine the existence of any association between age group, gender of study participants and prevalence of specific pathogens, a Chi-Square/Fisher's Exact test was computed. Results were presented in a bar graph and table.

- Objective 2: The MIC values were summarized as mean \pm SD and analyzed using one-way ANOVA (Analysis of Variance) to determine if there were significant differences between the mean MICs for the isolates with respect to the different groups of antibiotics studied and the final results were presented in a table. The level of significance was preset at $5 \%$ and $p$-values less than 0.05 were considered statistically significant in each of the above statistical tests.

\section{Results}

\section{Growth characteristics of pathogens in participants' samples.}


Figure 1 shows the growth characteristics of participants' samples. A total of 75 samples were collected from 75 participants and there was growth of pathogens in $69(92 \%)$ of samples while $6(8 \%)$ of participants' samples exhibited no growth.

Prevalence of pathogens isolated from infected chronic wounds.

Figure 2 below shows the overall prevalence of pathogens that were isolated from the participants' infected chronic wounds. The data shows that of the 69 samples that exhibited growth, the most prevalent pathogens isolated were Staphylococcus aureus $(40.6 \%, \mathrm{n}=28 / 69)$ Klebsiella $\operatorname{spp}(29 \%, \mathrm{n}=$ 20/69) while the least prevalent pathogens included Providencia $\operatorname{spp}(1.4 \%, \mathrm{n}=1 / 69)$ and Enterobacter agglomerans $(2.9 \%, \mathrm{n}=2 / 69)$.

Prevalence of bacterial isolates by age and gender of study participants.

Table 3 below shows the prevalence of pathogens that were isolated from the participants' infected chronic wounds with respect to age group and gender. Chronic wound infections caused by staphylococcus aureus were more prevalent among female patients (53.6\%) aged below 40 years $(67.9 \%)$ while chronic wound infections by Klebsiella spp were most prevalent among male patients $(60 \%)$ aged above 40 years(70\%). However the prevalence of each bacterial isolate was not significantly associated with a particular age group or gender of the study participants ( $p$-values $>0.05$ ).

Table 3: Prevalence of pathogens isolated from infected chronic wounds according to gender and age group of study participants.

\begin{tabular}{|c|c|c|c|c|c|c|}
\hline \multirow[t]{2}{*}{ Isolates $(\mathrm{N}=69)$} & \multicolumn{2}{|c|}{ Frequency, n (\%) } & \multirow[t]{2}{*}{$P$ value } & \multicolumn{2}{|c|}{ Frequency, n (\%) } & \multirow[t]{2}{*}{$P$ value } \\
\hline & $\begin{array}{l}\leq 40 \\
\text { yrs. }\end{array}$ & $\begin{array}{l}>40 \\
\text { yrs. }\end{array}$ & & Female & Male & \\
\hline Klebsiella species & $8(40.0)$ & $12(60.0)$ & 0.077 & $6(30.0)$ & $14(70.0)$ & 0.111 \\
\hline Staphylococcus aureus & $19(67.9)$ & $9(32.1)$ & & $15(53.6)$ & 13 & \\
\hline Enterobacter & $1(50.0)$ & $1(50.0)$ & 0.116 & $1(50.0)$ & $(46.4)$ & 0.233 \\
\hline agglomerans & $8(53.3)$ & 7 (46.7) & 0.850 & $7(46.7)$ & $1(50.0)$ & 0.884 \\
\hline Proteus species & $1(100.0)$ & $0(0.0)$ & 0.778 & $1(100.0)$ & $8(53.3)$ & 0.878 \\
\hline Providencia species & $2(66.7)$ & $1(33.3)$ & 0.565 & $1(33.3)$ & $0(0.0)$ & 0.449 \\
\hline Pseudomonas aeruginosa & & & 0.599 & & $2(66.7)$ & 0.577 \\
\hline
\end{tabular}




\section{The MICs of bacterial isolates to third generation cephalosporins}

In Table 4, the mean differences in minimum inhibitory concentration of the pathogens with respect to the different brands of cephalosporin were tested using analysis of variance (ANOVA) or the F-test and the results are presented.

In the ceftriaxone brand (Epicephin $\left.{ }^{\circledR}\right)$, staphylococcus aureus exhibited the lowest mean MIC $(15.77 \mu \mathrm{g} / \mathrm{ml})$ while a highest mean inhibitory concentration was observed for Enterobacter agglomerans species $(47.25 \mu \mathrm{g} / \mathrm{ml})$ followed by pseudomonas aeruginosa at $44.65 .0 \mu \mathrm{g} / \mathrm{ml}$. For the Cefoperazone+sulbactam (Sulcef $\left.{ }^{\circledR}\right) 2 \mathrm{~g}$ brand, Klebsiella species had the lowest mean MIC $(2.91 \mu \mathrm{g} / \mathrm{ml})$ and the highest mean inhibitory concentration was exhibited by Enterobacter agglomeran $(11.19 \mu \mathrm{g} / \mathrm{ml})$, Proteus species $(8.60 \mu \mathrm{g} / \mathrm{ml})$ and Pseudomonas aeruginosa $(8.50 \mu \mathrm{g} / \mathrm{ml})$ respectively. For Cefotaxime $1 \mathrm{~g}$ (omnatax®), the highest mean inhibitory concentration was for Proteus specie $(6.3 \mu \mathrm{g} / \mathrm{ml})$.

Klebsiella species $(\mathrm{MIC}=0.34 \mu \mathrm{g} / \mathrm{ml})$ and Enterobacter agglomerans $(\mathrm{MIC}=0.70 \mu \mathrm{g} / \mathrm{ml})$ were the only susceptible isolates to cefpodoxime $200 \mathrm{mg}$ (ximeprox ${ }^{\circledR}$ ). Generally, with respect to each brand of third generation cephalosporin, isolates with mean lower MIC values were more susceptible than isolates that exhibited higher mean MICs.

However, the differences in Mean MIC observed across various groups were not statistically significant $(p=>0.05)$; hence the growth of each isolate is inhibited by a specific MIC value with respect to a particular third generation cephalosporin. (That is to say, no specific mean MIC value is more effective in inhibiting the growth of two or more isolates with respect to a particular brand of third generation cephalosporin).

\section{Table 4: The MICs for susceptible isolates to third generation cephalosporins.}




\begin{tabular}{|c|c|c|c|}
\hline hird generation cephalosporin & Bacterial isolate & $\begin{array}{l}\text { Mean } \pm \text { SD } \\
(\mu g / m l)\end{array}$ & $P$ Value \\
\hline eftriaxone 1g (Epicephin $\AA$ ) & $\begin{array}{l}\text { Klebsiella species } \\
\text { Staphylococcus aureus } \\
\text { Enterobacter } \\
\text { agglomerans } \\
\text { Proteus species } \\
\text { Pseudomonas aeruginosa }\end{array}$ & $\begin{array}{l}22.97 \pm 27.15 \\
15.77 \pm 23.32 \\
47.25 \pm 51.97 \\
31.50 \pm 14.85 \\
44.65 \pm 55.65\end{array}$ & 0.2469 \\
\hline $\begin{array}{l}\text { əfoperazone+Sulbactam 2g } \\
\text {;ulcef }^{\circledR} \text { ) }\end{array}$ & $\begin{array}{l}\text { Klebsiella species } \\
\text { Staphylococcus aureus } \\
\text { Enterobacter } \\
\text { agglomerans } \\
\text { Proteus species } \\
\text { Providencia species } \\
\text { Pseudomonas aeruginosa }\end{array}$ & $\begin{array}{c}2.91 \pm 2.93 \\
4.23 \pm 8.41 \\
11.19 \pm 12.32 \\
8.60 \pm 13.59 \\
4.97 \pm 0.00 \\
8.50 \pm \\
10.11\end{array}$ & 0.4144 \\
\hline efotaxime $1 \mathrm{~g}$ (omnatax ${ }^{\circledR}$ ) & $\begin{array}{l}\text { Klebsiella species } \\
\text { Staphylococcus aureus } \\
\text { Enterobacter } \\
\text { agglomerans } \\
\text { Proteus species }\end{array}$ & $\begin{array}{l}1.60 \pm 1.71 \\
2.96 \pm 4.66 \\
0.72 \pm 0.79 \\
6.34 \pm 7.97\end{array}$ & 0.1946 \\
\hline $\begin{array}{l}\text { əfixime 400mg (gramocef-0- } \\
\left.0^{\circledR}{ }^{\circledR}\right)\end{array}$ & $\begin{array}{l}\text { Klebsiella species } \\
\text { Staphylococcus aureus } \\
\text { Enterobacter } \\
\text { agglomerans } \\
\text { Proteus species }\end{array}$ & $\begin{array}{l}0.38 \pm 0.48 \\
0.40 \pm 0.53 \\
0.04 \pm 0.00 \\
0.64 \pm 0.00\end{array}$ & 0.8680 \\
\hline әfpodoxime $200 \mathrm{mg}$ (ximeprox ${ }^{\circledR}$ ). & $\begin{array}{l}\text { Klebsiella species } \\
\text { Enterobacter } \\
\text { agglomerans }\end{array}$ & $\begin{array}{l}0.34 \pm 0.47 \\
0.70 \pm 0.00\end{array}$ & 0.6505 \\
\hline
\end{tabular}

\section{Discussion}

Microbiological evaluation of wound swabs revealed that $92 \%$ of wound swabs had growth while $8 \%$ of the chronic wound swabs exhibited no growth (Fig. 1). This pattern of growth could have been influenced by the presence of isolates encased in biofilms whose growth is poor by routine culture. This observation is supported by several studies which reported that $60 \%$ of chronic wounds have isolates encased in biofilms whose growth is poor with routine culture and frequently promote development of bacterial resistance $(17,18)$. Therefore clinician involved in management of patients with infected chronic wounds need to initiate effective antibiotic therapy to prevent development of biofilms. 
The most prevalent isolates found in infected chronic wounds were staphylococcus aureus (40.6\%), Klebsiella spp (29\%) and Proteus spp (21.7\%); (Fig. 2). In comparison, lower prevalence rates of staphylococcus aureus (27.5\%), klebsiella spp (18.5\%) and proteus spp (15\%) were reported in a tertiary Hospital in Nigeria (19). Providencia spp (1.4\%) and Enterobacter agglomerans (2.9\%) were identified from the study participants on the surgical ward of MRRH whereas Escherichia coli and acinobacter are not common but widely prevalent in other clinical settings $(19,20)$.

Therefore the observed difference in the pattern of prevalence across the various clinical settings dictates that selection of empirical therapy should entirely rely on the local prevalence pattern of infected chronic wound pathogens and periodic surveillance is required to determine the current prevalence of pathogens.

Chronic wound infections caused by staphylococcus aureus were more prevalent among female patients (53.6\%) aged below 40 years $(67.9 \%)$ while chronic wound infections by Klebsiella spp were most prevalent among male patients $(60 \%)$ aged above 40 years (70\%); (Table 3$)$. However, statistical analysis revealed that the prevalence of chronic wound isolates was not affected by gender and age of study participants $(P=>0.05)$. A similar study in Niger delta University Teaching Hospital also reported that gender and age of patients had no influence on the prevalence of wound isolates (21).

Because MIC values can be used in clinical settings to measure bacterial resistance and perform therapeutic drug monitoring to either optimize antibiotic therapy in case of resistant pathogens or individualize antibiotic therapy in case of organ dysfunction, this study also determined MICs of the five third generation cephalosporins against bacterial isolates. Our findings in Table 4 showed lower MICs for staphylococcus aureus and Klebsiella species against ceftriaxone1g (Epicephin ${ }^{\circledR}$ ) with corresponding low rates of resistance against ceftriaxone as compared to other isolates such as Proteus spp (Fig. 3). The MIC values for ceftriaxone $1 \mathrm{~g}$ (Epicephin ${ }^{\circledR}$ ) against some isolates observed in our study were even lower than those reported in Nepal teaching Hospital (22). This finding is useful for monitoring the effectiveness of ceftriaxone $1 \mathrm{~g}$ (Epicephin ${ }^{\circledR}$ ) in patients with Klebsiella spp and staphylococcus aureus chronic wound infections. Since all cephalosporins exhibits a time-dependent killing of pathogens, maximum plasma concentration of ceftriaxone (Epicephin $\left.{ }^{\circledR}\right) 1 \mathrm{~g}$ should exceed its mean MIC of $15.77 \mu \mathrm{g} / \mathrm{ml}$ or $22,97 \mu \mathrm{g} / \mathrm{ml}$ for $50-70 \%$ of the dosing interval (22).

Additionally, the Mean MIC values of Cefoperazone + sulbactam (sulcef $®$ ) were lower for Klebsiella spp $(2.91 \mu \mathrm{g} / \mathrm{ml})$ and staphylococcus aureus $4.27 \mu \mathrm{g} / \mathrm{ml}$. However MIC values of cefoperazone + sulbactam $2 \mathrm{~g}\left(\right.$ Sulcef $\left.{ }^{\circledR}\right)$ reported from other studies were higher $(16 \mu \mathrm{g} / \mathrm{ml})$ as compared to MIC values $(2.91-$ $11.19 \mu \mathrm{g} / \mathrm{ml}$ ) of pathogens in surgical ward of MRRH (23), hence a lower rate of resistance in surgical ward of MRRH as compared to other regions. Generally, all isolates studied were susceptible at various MIC values against Cefoperazone + Sulbactam $2 \mathrm{~g}$ (Sulcef $\circledast$ ), therefore this drug can be reserved as a choice for empirical therapy in the management of infected chronic wounds in the surgical ward of MRRH.

It was also observed that Staphylococcus aureus and Proteus spp were associated with higher MIC values against Cefixime $(0.40 \mu \mathrm{g} /$ and $0.64 \mu \mathrm{g} / \mathrm{ml}$ respectively) and complete resistance to cefpodoxime 
(ximeprox $\left.{ }^{\circledR}\right)$. In comparison with previous studies, the MIC values from previous studies are much lower $(0.06-0.25 \mu \mathrm{g} / \mathrm{ml})$ than MIC values obtained from this study, hence Cefixime400mg (gramocef-0-400®) and cefpodoxime $200 \mathrm{mg}$ (ximeprox ${ }^{\circledR}$ ). resistance in MRRH is higher compared to other clinical settings (Counts et al., 1988). Consequently, cefixime (gramocef-0-400®) and cefpodoxime $200 \mathrm{mg}$ (ximeprox®) should not be used in treatment of chronic wound infected with these isolates (Table 4) in MRRH unless culture and sensitivity tests suggest otherwise.

We analyzed the mean MIC values of the susceptible isolates against each of the five third generation cephalosporins using one-way ANOVA to determine the mean difference in MICs. Although the results of this study did not find statistically significant differences in mean MICs, many studies, including (26), recommend that lower MIC values are associated with better therapeutic outcomes.

\section{Study Limitations:}

- Pathogens encased in biofilms were not studied due to lack of standard microbiological methods for identification of microorganisms in biofilms. Therefore, the study results regarding prevalence of pathogens in infected chronic wound were affected.

- Patients who were currently on antibiotic therapy were not excluded from this study, which could have affected bacterial growth.

\section{Conclusion}

The most prevalent pathogens isolated from infected chronic wounds on the surgical ward of MRRH were staphylococcus aureus, klebsiella species and proteus species and the most effective antibiotics were cefoperazone + sulbactam, ceftriaxone and cefotaxime while cefixime and cefpodoxime were the most ineffective antibiotics against infected chronic wound isolates.

Stapylococcus aureus, enterobacter agglomerans, klebsiella species were the most susceptible isolates against ceftriaxone, cefoperazone + sulbactam and cefotaxime. The most resistant isolates were providencia species, proteus species and pseudomonas aeruginosa.

\section{Abbreviations}

ANOVA

Analysis of Variance

CLSI

Clinical Laboratory Standard Institute.

HIV

Human Immunodeficiency Virus.

MIC

Minimum Inhibitory Concentration. 
MUST

Mbarara University of Science and Technology.

MRRH

Mbarara Regional Referral Hospital.

PCR

Polymerase Chain Reaction.

SPP

Species.

SD

Standard Deviation.

REC

Research Ethics committee.

\section{Declarations}

\section{Ethical approval}

This study was initially submitted to for approval. The study and all the data collection tools were approved by the Faculty research committee and Research Ethics Committee (REC) of MUST

All eligible participants were given adequate information about this study so that they can make informed consent to participate. Participants who declined consent were excluded from this study.

2. Availability of data and materials: The datasets used and analyzed during the current study are available from the corresponding author on reasonable request.

3. Competing interest: All the authors had no competing interest.

4. Funding: Not applicable.

\section{Authors Contribution:}

WK- development of study protocol, Carrying out laboratory procedures (preparation of stock solution and broth microdilution), compilation of study findings, statistical analysis, writing the final research report and writing of the manuscript.

MJ-Performed laboratory procedures (culture and sensitivity, bacterial identification and broth microdilution).

Dr. TM- Reviewed the initial study protocol carried out the clinical diagnosis of infected chronic wounds in the surgical ward of MRRH and reviewed the final study report and manuscript.

TSS- Reviewed the initial study protocol, Interpretation of study finding, overall technical guidance throughout the entire process of the study and reviewing the manuscript. 


\section{Consent for publication: Not applicable.}

\section{Authors information}

\section{W K:}

Former Postgraduate student of clinical pharmacy at Mbarara University of science and technology and currently the head of pharmacy department at Kiboga general Hospital in Uganda. WK is qualified with Bachelor of pharmacy, diploma in clinical medicine and community health, diploma of higher education in HIVand AIDS care management and completed a master of pharmacy in clinical pharmacy.

My research interest is in antibiotic resistance and Hospital antibiotic stewardship practices.

TSS: Currently a PhD fellow and lecturer at the Mbarara university of science and technology. Holds a Master of Science in Pharmacology and Bachelor of Pharmacy.

Dr. TM: Currently practising as a plastic surgeon at Mbarara Regional Referral Hospital and lecturer at MUST. Holds a Master of medicine in plastic surgery and a Bachelor of medicine and surgery.

MJ: Currently, JM is the head of MUST medical laboratory. Hold a bachelor of science in medical laboratory science

\section{References}

1. Perim MC, Borges J da C, Celeste SRC, Orsolin E de F, Mendes RR, Mendes GO, et al. Aerobic bacterial profile and antibiotic resistance in patients with diabetic foot infections. Revista da Sociedade Brasileira de Medicina Tropical. 2015 Oct;48(5):546-54.

2. Kirketerp-Møller K, Jensen Pø, Fazli M, Madsen KG, Pedersen J, Moser C, et al. Distribution, Organization, and Ecology of Bacteria in Chronic Wounds. Journal of Clinical Microbiology. 2008 Aug 1;46(8):2717-22.

3. Ampaire L, Muhindo A, Orikiriza P, Mwanga-Amumpaire J, Bebell L, Boum Y. A review of antimicrobial resistance in East Africa. Afr J Lab Med [Internet]. 2016 Sep 15 [cited 2019 Apr 29];5(1). Available from: https://www.ncbi.nlm.nih.gov/pmc/articles/PMC5436405/

4. Elbireer AM, Opio AA, Brough RL, Jackson JB, Manabe YC. Strengthening Public Laboratory Service in Sub-Saharan Africa: Uganda Case Study. Lab Med. 2011 Dec 1;42(12):719-25.

5. Manirakiza L, Nambasa V, Nanyonga S, Serwanga A, Alphonsus M, Denis N, et al. Drug Use Evaluation (DUE) of Ceftriaxone in Mubende Regional Referral Hospital, Uganda: A Cross-Sectional Survey. J Pharm Pharmacol Res [Internet]. 2019 [cited 2019 Nov 5];03(03). Available from: http://www.fortunejournals.com/articles/drug-use-evaluation-due-of-ceftriaxone-in-mubenderegional-referral-hospital-uganda-a-crosssectional-survey.html

6. Filius PMG, Gyssens IC. Impact of increasing antimicrobial resistance on wound management. Am J Clin Dermatol. 2002;3(1):1-7. 
7. Rondas AA, Schols JM, Stobberingh EE, Halfens RJ. Prevalence of chronic wounds and structural quality indicators of chronic wound care in Dutch nursing homes. International Wound Journal. 2015 Dec 1;12(6):630-5.

8. Hoyle R, Gottfredson N. Sample Size Considerations in Prevention Research Applications of Multilevel Modeling and Structural Equation Modeling. Prevention science: the official journal of the Society for Prevention Research. 2014 Apr 23;16.

9. Acharya AS, Prakash A, Saxena P, Nigam A. Sampling: why and how of it? Indian J Med Spec [Internet]. 2013 Jul 7 [cited 2019 Jun 14];4(2). Available from: http://www.ijms.in/articles/4/2/sampling-why-and-how-of-it.html

10. Handfield S. Formation of a provincial nursing skin and wound committee. J Wound Ostomy Continence Nurs. 2013 Dec;40(6):568-71.

11. Reller LB, Weinstein M, Jorgensen JH, Ferraro MJ. Antimicrobial Susceptibility Testing: A Review of General Principles and Contemporary Practices. Clin Infect Dis. 2009 Dec 1;49(11):1749-55.

12. Shah S, Barton G, Fischer A. Pharmacokinetic considerations and dosing strategies of antibiotics in the critically ill patient. Journal of the Intensive Care Society. 2015 May 1;16(2):147-53.

13. Scully BE, Fu KP, Neu HC. Pharmacokinetics of ceftriaxone after intravenous infusion and intramuscular injection. Am J Med. 1984 Oct 19;77(4C):112-6.

14. Fu KP, Aswapokee P, Ho I, Matthijssen C, Neu HC. Pharmacokinetics of cefotaxime. Antimicrob Agents Chemother. 1979 Nov;16(5):592-7.

15. Borin MT, Hughes GS, Spillers CR, Patel RK. Pharmacokinetics of cefpodoxime in plasma and skin blister fluid following oral dosing of cefpodoxime proxetil. Antimicrob Agents Chemother. 1990 Jun;34(6):1094-9.

16. Naz U, Ashraf M, Javed I, Aslam B, Khan J, Muhammad F, et al. Comparative pharmacokinetics of cefspan and ceforal-3 in adult human healthy female subjects. 2017 Jan 1;36:776-82.

17. Clinton A, Carter T. Chronic Wound Biofilms: Pathogenesis and Potential Therapies. Lab Med. 2015 Nov 1;46(4):277-84.

18. Penterman J, Nguyen D, Anderson E, Staudinger BJ, Greenberg EP, Lam JS, et al. Rapid Evolution of Culture-Impaired Bacteria During Adaptation to Biofilm Growth. Cell Rep. 2014 Jan 30;6(2):293-300.

19. Thanni LOA, Osinupebi OA, Deji-Agboola M. Prevalence of bacterial pathogens in infected wounds in a tertiary hospital, 1995-2001: any change in trend? Journal of the National Medical Association. 2003 Dec;95(12):1189.

20. Najari HR, Karimian T, Parsa H, QasemiBarqi R, Allami A. Bacteriology of moderate-to-severe diabetic foot infections in two tertiary hospitals of Iran. Foot (Edinb). 2019 May 10;40:54-8.

21. Pondei K, Fente BG, Oladapo O. Current microbial isolates from wound swabs, their culture and sensitivity pattern at the niger delta university teaching hospital, okolobiri, Nigeria. Trop Med Health. 2013 Jun;41(2):49-53. 
22. Thapa B, Mahat K. In-vitro activity of three brands of ceftriaxone against different clinical isolates. JNMA J Nepal Med Assoc. 2010 Sep;49(179):225-7.

23. Asín-Prieto E, Rodríguez-Gascón A, Isla A. Applications of the pharmacokinetic/pharmacodynamic (PK/PD) analysis of antimicrobial agents. Journal of Infection and Chemotherapy. 2015 May;21(5):319-29.

24. Sader HS, Carvalhaes CG, Streit JM, Castanheira M, Flamm RK. Antimicrobial activity of cefoperazone-sulbactam tested against Gram-Negative organisms from Europe, Asia-Pacific, and Latin America. International Journal of Infectious Diseases. 2020 Feb;91:32-7.

25. Counts GW, Baugher LK, Ulness BK, Hamilton DJ. Comparative in vitro activity of the new oral cephalosporin cefixime. Eur J Clin Microbiol Infect Dis. 1988 Jun 1;7(3):428-31.

26. Wiedemann B, Luhmer E, Zühlsdorf MT. Microbiological evaluation of cefpodoxime proxetil. Drugs. 1991;42 Suppl 3:6-12.

27. Walker KJ, Lee YR, Klar AR. Clinical Outcomes of Extended-Spectrum Beta-Lactamase-Producing Enterobacteriaceae Infections with Susceptibilities among Levofloxacin, Cefepime, and Carbapenems [Internet]. Vol. 2018, Canadian Journal of Infectious Diseases and Medical Microbiology. Hindawi; 2018 [cited 2021 Jan 31]. p. e3747521. Available from: https://www.hindawi.com/journals/cjidmm/2018/3747521/

\section{Figures}

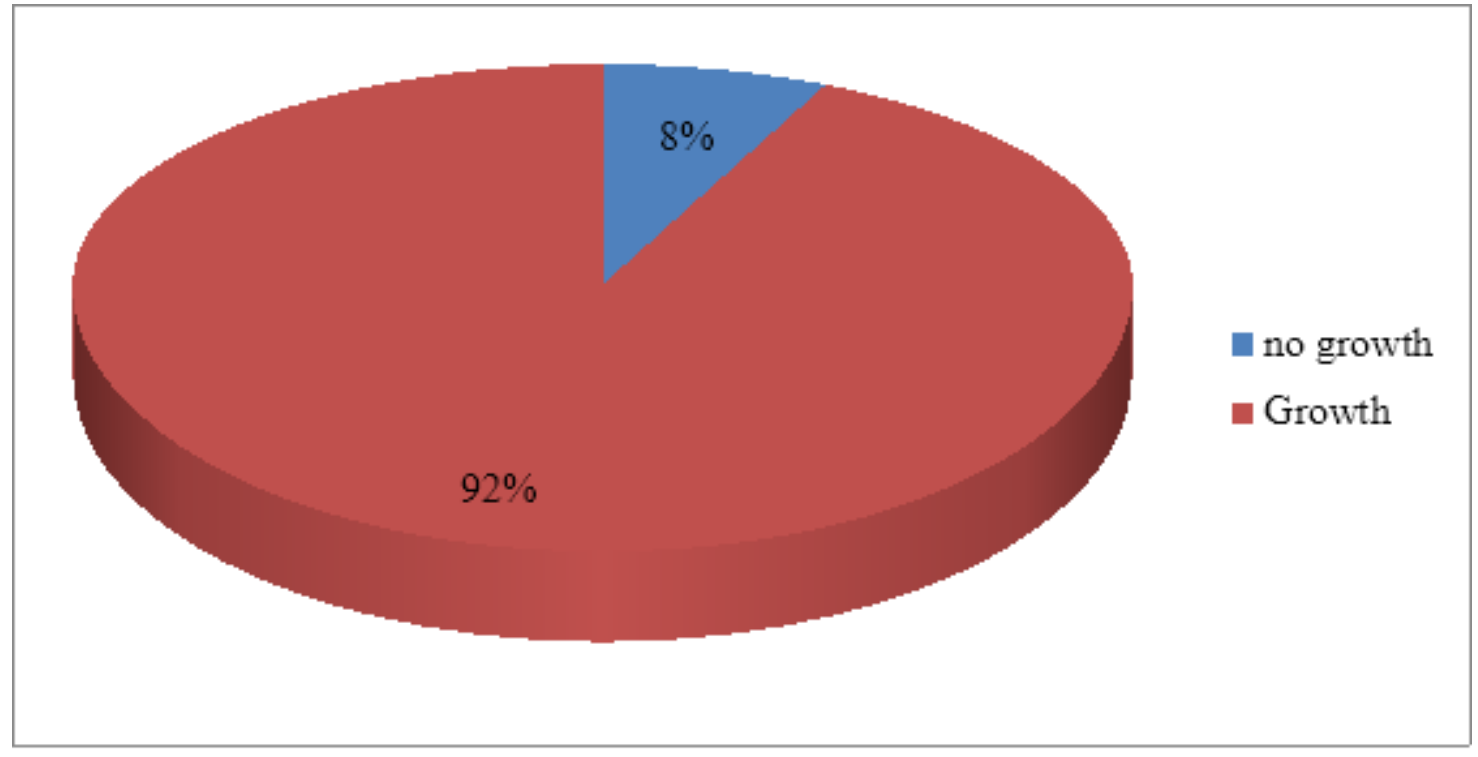

Figure 1

Growth Characteristics of pathogens in participants' samples. 


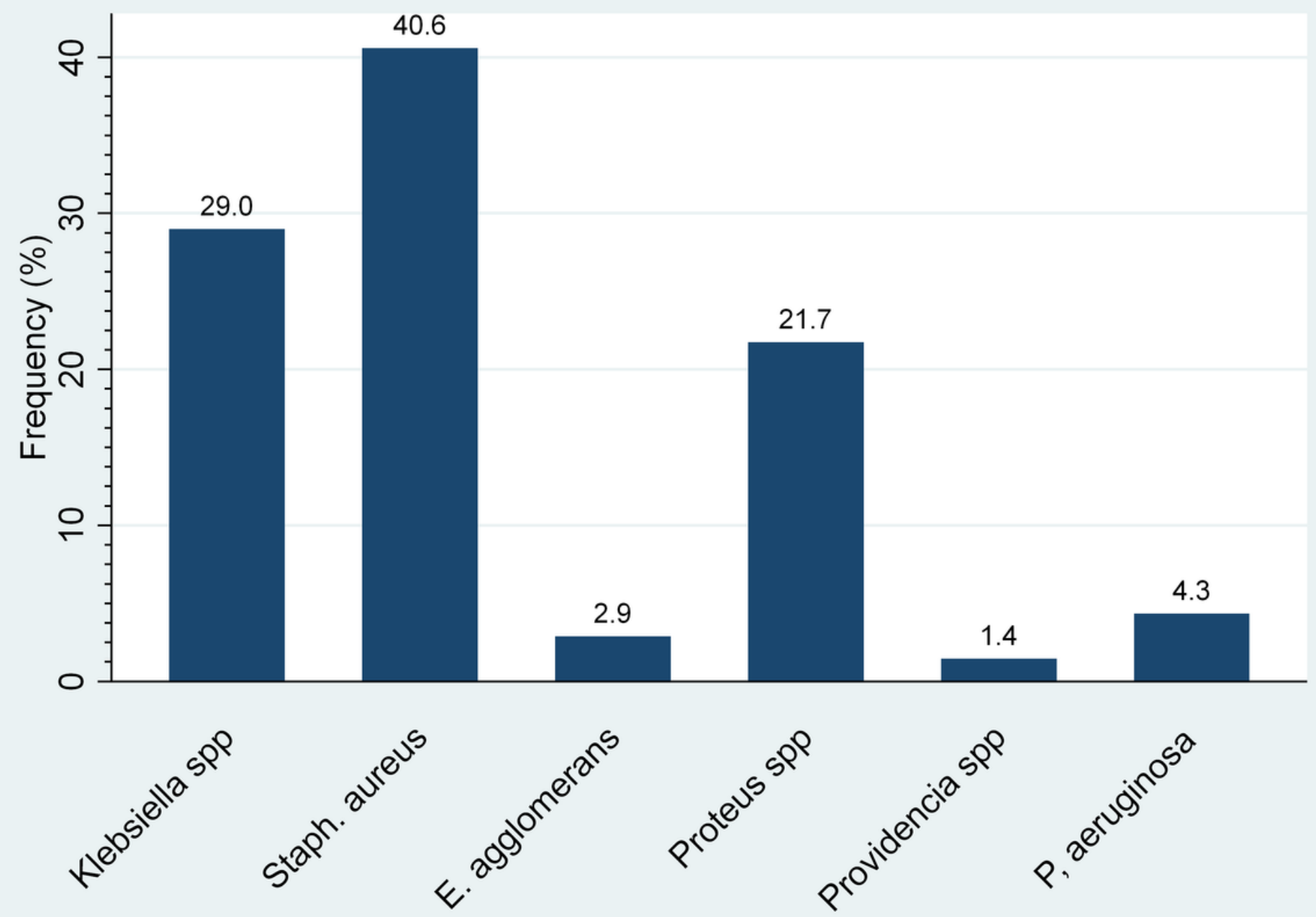

Figure 2

The overall prevalence of bacterial isolates from infected chronic wound. 